Literatura y Lingüística $\mathrm{N}^{\circ} 24$

ISSN 0716-5811 / pp. 33-59

\title{
La anomia en las novelas de crímenes en Colombia*
}

\author{
Gustavo Forero Quintero**
}

\section{Resumen}

Este artículo propone el análisis de algunas novelas colombianas escritas entre los años 1990 y 2005 a partir de teoría de la anomia. Para ello, el autor ofrece una consideración de lo que es la anomia; en segundo lugar, explica la pertinencia del concepto para la literatura y, en tercer lugar, lo aplica a algunas de esas novelas. Finalmente, a partir de tal metodología, propone una caracterización de lo que denomina la novela de crímenes en Colombia.

Palabras clave: Novela de crímenes, Anomia, Novela colombiana

\section{The anomie in colombian crime novels}

\begin{abstract}
This paper proposes an analysis of some Colombian novels written between 1990 and 2005 based on anomie theory. From this sociological perspective, it defines the Crime Novel genre. Thus, the author provides a brief account of what anomie is. Secondly, he explains this concept in literature and, third, he applies it to contemporary Colombian novels. Finally, he proposes a characterization of the Crime Novel.
\end{abstract}

Keywords: Crime Novel, Anomie, Colombian Novel

Recibido: 24-03-2011Ａceptado: 04-05-2011

* Este trabajo hace parte del proyecto de investigación "La anomia en la novela de crímenes en Colombia (1990-2005)", inscrito en la línea de investigación Novela de Crímenes del Grupo Estudios Literarios, GEL, que coordina el autor y que pertenece a la Vicerrectoría de Investigación de la Universidad de Antioquia.

** Profesor Asociado del área de Literatura de la Facultad de Comunicaciones de la Universidad de Antioquia. Doctor por la Universidad de Salamanca y Magíster en Études Romanes de la Universidad de la Sorbona (París IV). Literato de la Universidad Nacional de Colombia y Abogado de la Universidad Externado.gustavoforero@comunicaciones.udea.net.co 
La anomia en las novelas de crímenes en Colombia / Gustavo Forero Quintero

La Ley de Colombia es la impunidad y nuestro primer delincuente impune es el presidente, que a estas horas debe de andar parrandiándose el país y el puesto. ¿En dónde? En Japón, en México... En México haciendo el cursillo.

(Fernando Vallejo, 2006, 19)

[P]aís desolado que sobrevive a punta de instinto, que lucha sin respaldo ni apoyo, sin subsidios, sin educación, en medio de una violencia enfermiza que enfrenta a todos contra todos, un país abandonado por el Estado, carcomido por el caos y la corrupción política y que se hunde cada vez más en el despeñadero de pauperismo y la indigencia.

(Mario Mendoza, 2007, 229)

De 1990 a 2005 se consolida en Colombia un género literario que se puede denominar la novela de crímenes, estrechamente vinculado con su realidad social. Éste se ocupa, primordialmente, del crimen en su acepción amplia (pues incluye el asesinato y el secuestro, pero también delitos contra el patrimonio económico o delitos políticos determinados como tales en la legislación nacional) y en este campo da cuenta de la situación de anomia que vive el mundo histórico que recrea; es decir, es un género que presenta el mundo de la criminalidad en un ambiente de ausencia de ley, de situaciones épicas que derivan de la carencia de normas o de la degradación de las normas sociales existentes en un momento dado.

Desde esta perspectiva, gracias a los postulados de "crisis" y "normalidad" de Emile Durkheim, "desviación" de Robert Merton, "continua renegociación" de Lidia Girola, "Estado híbrido" de Peter Waldmann; pero, sobre todo, con base en las nociones de "esclusa" y "deseo infinito" de Jean Duvignaud, "interdiscurso" de Jürgen Link, y de "frontera" y "zonas de transición" de Édison Neira, se pueden analizar algunas de estas novelas, ofrecer pautas para su clasificación y realizar su posterior caracterización como género.

\section{La teoría de la anomia}

En su origen la teoría de la anomia no estuvo vinculada con el crimen y mucho menos con la literatura. No obstante, se relacionaba íntimamente con ella en lo que a novela de crímenes corresponde. Para Emile Durkheim (1858-1917) la anomia supone un "état d'anarchie", un "état de dérèglement"1, lo que al momento de traducirse al español supone un

1 En el original en francés (1967). Sobre la traducción de estas palabras considero pertinentes los comentarios de Waldmann $(2007,97)$. 
campo semántico tan amplio que incluye desde el anarquismo como ideología hasta la ausencia de reglas, la "ausencia de poder público" (DRAE), el desarreglo o el desgobierno (Cuyas, 1974; Collins, 2001), tópicos estos de gran interés para la literatura. Así, cuando una sociedad sufre la pérdida de los valores compartidos cae en este estado -de anomia-y los individuos que la componen experimentan un creciente grado de ansiedad e insatisfacción. El suicidio, por ejemplo, como conducta anómica supone "factores extra sociales" (1998, libro I) y "Causas sociales y tipos sociales" de la conducta (Libro II) y este modelo de comprensión se ha extendido al análisis de los factores y las causas mismas de los crímenes. Los primeros aluden al origen personal o aun familiar de la decisión, en tanto los segundos a la raíz colectiva (grupos sociales, trabajo, etc.) de la acción anómica. Unos y otros dependen del carácter orgánico de la sociedad, pues "[t] oda moral de progreso y de perfeccionamiento es [... ] inseparable de cierto grado de anomia" (1998, 407).

Por su parte, Robert Merton (1919-2003) incluye el concepto de anomia dentro de la teoría del comportamiento social desviado que se quiere entender dentro de su propia lógica:

El poder puede ser legitimado por algunos grupos, sin serlo para todos los grupos de una sociedad. Por lo tanto, puede ser erróneo describir el inconformismo con instituciones sociales particulares como conducta divergente; puede representar el comienzo de una norma nueva, con sus derechos distintivos de la validez moral (1964, 132).

A diferencia de Durkheim (a quien critica duramente por su explicación orgánica de un orden social, 2002), la explicación del hecho anómico en Merton depende del desarrollo funcional y económico de la sociedad moderna, donde las normas existen pero el sujeto no logra a través suyo las metas de bienestar que se le prometen u ofrecen (Merton, 2002, 241). De tal manera, "la conducta anómala puede considerarse desde el punto de vista sociológico como un síntoma de la disociación entre las aspiraciones culturalmente prescritas y los caminos socialmente estructurales para llegar a dichas aspiraciones" (1964, 143). En este contexto puede presentarse la anomia social o la anomia individual, y en uno u otro caso una acción individual puede derivar o no en el crimen².

2 Esta clasificación entre anomia social o la anomia individual la propuso el autor (1968, pp. 218 y ss), pero no la desarrolló sistemáticamente. La anomia social aludiría a aquella ausencia de medios reales para los ciudadanos y fines inalcanzables, en tanto la anomia individual obedecería a la incapacidad misma del individuo de superar íntimamente la brecha que existe entre sus aspiraciones y los caminos aceptables para llegar a ellas. 
Además, Merton reconoce que más que ninguna otra expresión cultural la literatura le ha heredado a la sociología la necesidad de escribir "vivaz e intensamente [...] la escena humana de que trata" $(1964,23)$. Con esto último el autor establece la relación entre la anomia, la sociología y la literatura, que van a sugerir los tratadistas posteriores.

Por su parte, retomando la teoría de Durkheim, Lidia Girola expone:

Si asociamos anomia con un período de transición, con la ruptura de marcos valorativos y normativos sin que se haya claramente impuesto un modelo de recambio, es evidente que la situación actual en las sociedades industrializadas es típicamente anómica. Pero también se puede pensar a la cultura actual de esas sociedades como anómica por dos razones diferentes. Una [...] como sinónimo de un extremo pluralismo, autonomía de las esferas valorativas, libertad individual para adoptar aquellos principios y normas para regir la vida que cada quien considerara más adecuadas y convenientes para sí mismo. Otra, porque lo que caracteriza a los habitantes de las grandes ciudades tanto como a los del campo, a nivel de vivencia existencial, es la depresión, el vacío o el estrés, la percepción del descompromiso, la sensación de que uno a nadie le importa. No el abismo de los remordimientos ni la conciencia culpable, que atormentaron durante tantos años a los sujetos educados en la moral del deber; sino el sinsentido de la vida y la duda con respecto a uno mismo, propios de la oferta exacerbada de opciones vitales (85).

Desde esta perspectiva, la autora argentina establece que hoy por hoy el estado de anomia caracteriza a las sociedades industrializadas en general, donde los individuos pueden tener conciencia de su autonomía, pero padecen cada vez más de algo tan literario como el "sinsentido de la vida". De este modo, la anomia no es una situación psicológica excepcional sino general y puede derivar o no en el crimen. Para el caso concreto de América Latina, Girola advierte:

Existe discriminación y discrecionalidad en cuanto a la aplicación de la ley. En la mayoría de nuestros países, con escasas excepciones, hay una larga tradición de ignorar la ley, o de, conociéndola, torcerla a favor de los poderosos. [... .] Existe el sentimiento generalizado de que el que se somete a la ley es un idiota o un débil. En la relación de las burocracias con los ciudadanos comunes, el trato es diferenciado según la posición social y económica, que 
se manifiesta, por ejemplo, cuando los pobres y los socialmente débiles tienen que solicitar un trabajo, un permiso, o cuando van a un hospital o a la policía. El trato que reciben frecuentemente es de indiferencia, desprecio o incluso violento. [...] La ley se aplica intermitente y diferenciadamente. Hay una continua renegociación de los límites entre legalidades formales e informales. El aparato legal no se aplica equitativamente (110-111).

De este modo, con ecos de la "innovación" en las clases bajas a las que se refería Merton ${ }^{3}$, en esta perspectiva de la conducta anómica el crimen puede ser una forma determinada de reacción ante los límites de la ley impuesta por un Estado inequitativo y, en particular, por las clases dominantes. Desde este punto de vista, se comprenden las actuaciones ilegales y, muy lejos de las artes y la literatura, que podrían recrear la situación (sobre todo por el alcance de nociones como "sinsentido de la vida" o "duda con respecto a uno mismo" que sólo a través suyo podrían ilustrarse), se advierte que el problema de la anomia es ante todo fruto de profundas divisiones sociales como las que existen en el continente latinoamericano (que también tiene su interés literario). Así, conforme con las teorías marxistas que le sirven de telón de fondo, es la naturaleza del Estado o la división de clases lo que determina en últimas la presencia de una conducta anómica, sea criminal o no. La novela como hecho social sería, como en Karl Marx y sus discípulos, una fuente de denuncia de este conflicto y la recreación de la manera como los grupos sociales subordinados históricamente han logrado determinadas reivindicaciones (así es, también, para George Lukács en La novela histórica de 1936/1937).

Todavía en el campo de la realidad contemporánea, el sociólogo alemán Peter Waldmann establece la existencia de sistemas enteros determinados por la anomia social:

El caso típico, susceptible de ser caracterizado como "anómico", es el que encontramos en los países en vías de desarrollo o en algún país del ex bloque del Este. Este caso apunta a fenómenos híbridos, en los cuales coexisten normas de comportamiento generales y específicas, oficiales e informales, cuyo modo de operar no es claro $(2007,105)$.

3 Me refiero al segundo "Modo de adaptación individual" (luego de la Conformidad y antes del Ritualismo, el Retraimiento y la Rebelión) que, en la teoría de Merton, supone que se aceptan ciertas metas culturales, pero se rechazan los medios institucionalizados para llegar a ellas. En este evento, se usan medios "institucionalmente proscritos, pero con frecuencia eficaces, de alcanzar por lo menos el simulacro del éxito: riqueza y poder" $(1964,150)$. 
Dentro de esta perspectiva, Waldmann habla de un "Estado anómico" (2003), es decir, de "[...] un Estado que según criterios de lo que debería ser su buen funcionamiento, no sólo presenta ciertas carencias y debilidades, sino que prácticamente invierte parte de sus criterios" (10). Así, el autor designa "con el término 'anomia' un estado de la sociedad que se caracteriza por la ausencia de una estructura normativa consistente y obligatoria" (101). En este contexto, "anomia significa que la comunidad ha renunciado a exigir comportamientos determinados, pues el (o los) individuo(s) no los respetan y/o las violaciones a las normas no son sancionadas" (109). De este modo, desde un punto de vista kantiano señala: "[s]i el orden ha de ser consistente, tendrá que haber ciudadanos que respeten las normas a raíz de su propia convicción moral, no a causa del riesgo de experimentar sanciones" (109). En este sentido se percibe (como en Durkheim) el carácter psicológico que acusa el problema, pues se acude al campo de la convicción moral para entenderlo. Además -como Merton-, Waldmann propone "la desviación social y [la] delincuencia" como formas tangibles del concepto de anomia (a diferencia de otras como la confusión lingüística y la desorientación y deslegitimación, 113) ${ }^{4}$, lo que serviría para explicar el propósito pedagógico de los sistemas sociales y -como sugería Merton- la proliferación de conductas delictivas en algunos sectores marginales ${ }^{5}$. Desde este punto de vista, el autor señala la importancia de la literatura para comprender en su esencia el fenómeno, pues el proceder anómico "de doble fondo ha sido mejor captado en novelas que en análisis sociológicos” (119). Para demostrar esto, el autor toma como ejemplo la novela El Señor Presidente (1946): en ella, Miguel Ángel Asturias "ha expuesto de manera convincente y apasionante cómo tiranos obsesionados con el poder socavan las bases morales de la sociedad e impiden que emerja una oposición, convirtiendo en inexpugnable su

4 El autor alude a la confusión lingüística como "el tipo de anomia más agotador y más doloroso para los involucrados y, al mismo tiempo, el más difícil de superar, ya que el 'ponerse de acuerdo acerca de las dificultades para llegar a un acuerdo', desde el punto de vista lógico, es un absurdo" (113). Por su parte, en el diagrama explicativo de las dimensiones del concepto de norma y las formas de anomia, la desorientación y deslegitimación surgen de la falta de convicción moral del grupo en la norma y la falta de su socialización (Ibid.).

5 Para Waldmann, Colombia, "[u]n Estado híbrido [...] difícil de entender" (221), "no sólo bate el record mundial de homicidios, sino que encabeza también las estadísticas en delitos como secuestros extorsivos y toma de rehenes" (169); asimismo, la venganza como motivo arcaico de la violencia se mantiene en ciertos lugares del país, como por ejemplo en el occidente de Boyacá ("Lejano Oeste" del país y mercado de piedras preciosas, 205), y la existencia de actores no estatales (guerrilla y grupos paramilitares) y actores externos (Estados Unidos principalmente) determinan su anomia. "La violencia se ha vuelto más anónima y selectiva, pero la cuestión de si ha disminuido durante el transcurso del proceso de urbanización y modernización está abierta y la respuesta sería más bien negativa" (320). 
posición en el poder al tergiversar sistemáticamente todos los dictados del derecho y la moral" (119).

En síntesis, desde una perspectiva clásica, la situación social, determinada por la ausencia, carencia o degradación de determinadas normas, provoca una sensación psicológica, excepcional en el individuo, y puede llevar, en algunos casos, al crimen, del que puede dar cuenta la literatura. Esta última conducta exige una sanción para que la sociedad vuelva a su "normalidad" y se restituya la armonía. Por el contrario, desde una perspectiva contemporánea (derivada en buena parte de las teorías de Merton), la sociedad industrializada es anómica en general y produce estados individuales de insatisfacción que pueden ocasionar o no el crimen. La inadaptación del individuo supone tal complejidad que es ante todo en la literatura donde puede entenderse el conflicto. La sociedad moderna se caracteriza en estos casos por la inequidad del Estado y la división de clases, así como por la falta de asimilación de los individuos, que producen distintas respuestas (entre ellas el delito). La ausencia de un Estado con reglas claras, o bien la existencia de uno que esté a favor de minorías dominantes, impide a otros grupos sociales y, en particular, a ciertos individuos vivir dentro de los límites de la legalidad. Sus intereses se alejan cada vez más de los límites oficiales y así surge el crimen (que representa paradójicamente el carácter "innovador" -como diría Merton- del individuo para lograr los fines económicos que se le proponen). Por esto, sobre las bases de la teoría de Girola o Waldmann, puede decirse que la anomia responde a una serie de fuerzas de distinto sentido: se explica como falta de convicción moral de los individuos frente a las normas, pero también como la situación propia de un aparato normativo que genera sinsentido de la vida y duda con respecto a uno mismo. Cuando esto sucede, aumenta el grado de esa insatisfacción del individuo con los límites que existen en un determinado momento de la historia nacional ${ }^{6}$. Y aunque este hecho es de carácter sociológico y jurídico, como señala Merton el problema puede advertirse en un momento dado en la literatura más que en otro campo del conocimiento, pues en efecto aquí se muestra vivaz e intensamente la escena humana de que trata. De tal modo, en Colombia, por ejemplo, el género literario de la novela daría cuenta no sólo de un país donde la inseguridad jurídica se

6 En este sentido se debe advertir que la novela, contextualizada dentro de un marco específico, en general alude a un sistema normativo que es nacional: normalmente la ley lo es y su observancia ocurre dentro de circunstancias de modo, tiempo y lugar precisas a ese contexto. Esto justificaría, en el campo de la anomia, análisis clásicos en torno a las literaturas nacionales, como la colombiana, la francesa o la alemana, que en ciertos casos injustamente han caído en descrédito. 
ha vuelto regla, sino, además, del estado psicológico de ciertos individuos que tienden a encauzar sus acciones a través de otros caminos, como por ejemplo el delito. Esta situación se analiza a continuación a partir de la aplicación del concepto de anomia en la literatura y, luego, con sus representaciones particulares en algunas novelas colombianas.

\section{La anomia en la literatura}

En relación con la aplicación de concepto de anomia a la literatura, y dentro de la dinámica de la crisis a la que aludía Durkheim, para Jean Duvignaud (1921-2007): "Si la palabra anomia' posee un sentido, designa las manifestaciones ‘nclasificables' que acompañan el difícil tránsito de un género de sociedad que se degrada a otro que la sucede en un mismo periodo y que aún no ha cobrado forma. Estamos en la esclusa" (1990, 13). En tal caso, existen relaciones entre "la creación imaginaria y la vida colectiva" (25) donde la ficción resulta subversiva para el sistema que le sirve de marco. Desde esta perspectiva, original para la crítica literaria ${ }^{7}$, en algunas novelas "el deseo infinito" del escritor se anticipa a la realidad que le sirve de contexto y le ayuda a construir "otra realidad":

[...] durante ciertos periodos en crisis, los hechos de novación, las fricciones, los comportamientos imaginarios representan, tanto en el nivel de los grupos como en el de los individuos, una fuerza que se puede llamar, si se quiere, el deseo infinito, pero cuya aparición destruye las antiguas clasificaciones admitidas y reconocidas y se anticipa con mucho a la experiencia adquirida al proponer, bajo el aspecto de la ficción, sugerencias o incitaciones hasta entonces desconocidas [...] La creación imaginaria suscita a menudo represiones similares o, como mínimo, incomprensión. Una nueva forma de ver el mundo nunca es popular. Porque deforma la imagen ya hecha y admitida de lo que debe ser la realidad, la visión del Greco o de los pintores cubistas es subversiva, como lo fue la música de Wagner o la de Stravinski. Como lo fueron los personajes criminales del teatro, de Edipo a Tamerlán, de Macbeth a Woyzeck. [...]

7 Duvignaud se apoya en los análisis sociológicos de la literatura (Lukács, Goldmann, etc.). Aunque la relación entre literatura y anomia no se encuentra como tal en estos, creo que para sustentarla también son interesantes las aportaciones de Jacques Leenhardt (1973), Peter Häberle (1983 y 2004) o Peter Brooks (2000). En Colombia, son encomiables, entre otros, los esfuerzos iniciales de Antonio José Cancino: El Derecho penal en la obra de Gabriel García Márquez (1973) y más recientemente el trabajo de Edison Neira (2004) que reseñamos adelante. 
Esta comparación entre lo que sucede en la sociedad y lo que pasa en la literatura se subordina, sin duda, a la teoría clásica que asumía la anomia como parte de la dinámica de una transformación social, de un orden anterior, represivo, a uno posterior, permisivo, donde la libertad del individuo poco a poco alcanza su lugar. El deseo infinito de los grupos y de los individuos es semejante al del escritor en la creación, pues en ambos una nueva forma de ver el mundo subvierte la anterior y como tal no es aceptada inicialmente en el contexto ${ }^{8}$. Desde esta perspectiva, sobre la resolución de la novela Duvignaud afirma:

[...] Esta represión encuentra su forma, en la literatura y en el teatro, en el lenguaje mismo: es decir, el dramaturgo o el escritor castiga y destruye él mismo al personaje, al cual, a lo largo de extensas páginas o durante dos horas, ha conferido un fascinante atractivo. [...] Aun castigado y condenado por el creador mismo, lo que representa la anomia no deja de ser peligroso y subversivo (1990, 27-28).

En efecto, a partir de este análisis se puede colegir que el orden rechaza la subversión y, hasta tanto no se produzca un cambio oficial, condena al responsable. Como lo expone el autor:

[...] Al menos, esta represión, incluso en el lenguaje literario mismo, adopta formas diversas: los griegos la dominan "destino" y algunos autores modernos "fatalidad". Lukács dice que el héroe trágico muere de lo que, "bajo la mirada de Dios", no puede admitir como compromiso con el mundo y se condena a sí mismo. Deberíamos decir, más bien, que es "la mirada de Dios" la que mata al personaje, puesto que este "Dios" no es otro que la conciencia común sublimada en la conciencia del autor: Laclos condena a Valmont y Merteuil, como Balzac mata a Rubempré y Vautrin, como Flaubert a Madame Bovary (29).

Esta tesis relativa al vínculo entre la anomia y la literatura describe el origen mismo de la novela europea moderna, inspirada en buena parte en el individualismo exacerbado y la acción de los héroes excepcionales. Extrapolando esta perspectiva romántica próxima a los planteamientos de la anomia individual de Durkheim, Salvador Vásquez de Parga (1986) señala para el género que nos ocupa: "La novela criminal en cualquiera de sus etapas, es un alegato a favor del individualismo. La justicia y el orden sólo se restablecen a nivel individual. Se trata de casos concretos,

8 En relación con esto, el estudio de Irene Martínez Sahuquillo habla también de anomia como "extrañamiento y desarraigo" del personaje y del propio escritor (1998). 
de crímenes determinados, y es un individuo quien ve satisfechas sus aspiraciones de justicia" (21). En tal sentido se observa aquí la persistencia de la lógica planteada por Durkheim entre la conducta anómica y el orden social. En contraposición a esto, en el campo del discurso analítico el crítico alemán Jürgen Link (1940) estudia el problema del normalismo que está en la base de la teoría de la anomia y desarrolla el concepto del "interdiscurso" en la literatura (2006). Así, mientras el primero describe la situación vigente hasta más o menos los años sesenta, el segundo se refiere al multiculturalismo contemporáneo. En cuanto a lo primero, en la línea de distinción entre normalidad y anormalidad de Durkheim y por oposición al funcionalismo estructuralista de Merton, define el "normalismo" como una red específicamente moderna de estrategias normativas generales y sectoriales, a las que denomina "protonormalismo" y "normalismo flexible" respectivamente. En cuanto a lo segundo, Link analiza el rol de la literatura en función de lo que se considera la normalidad y con base en escritores como Balzac, Céline o Heidegger, ilustra métodos particulares de relación de los sujetos con aquella normalización: lo normal aparece en el discurso. De este modo, para la solución de conflictos propone una anomia flexible como la derivada del mundo literario.

En tal línea contemporánea, Édison Neira estudia la relación entre la estructura social y la literatura en la obra del escritor colombiano José Antonio Lizarazo (2004). Este autor le permite al crítico hablar de anomia en la novela colombiana derivada de transformaciones sociales de carácter progresista en medio del siglo XX. Así, en El día del odio (1952) Neira analiza las fronteras entre distintos niveles sociales de los años cuarenta de ese siglo y establece: los personajes marginales, derivados de la escisión social, son asumidos poco a poco como delincuentes, y el ladronzuelo $(2004,180)$, la prostituta o el niño (181) se hacen rápidamente a esta condición anómica. La "des-urbanización" del personaje de Tránsito (protagonista de El día del odio) se da en virtud del hecho de que "adopta un modelo de urbanidad distinto: el de la sociedad no normalizada o sociedad anómica" (156); [...] por su anomia o inestabilidad, el bajo mundo le ofrece más posibilidades de anonimato para establecer contactos" (157). Como en las novelas negras norteamericanas que le son contemporáneas, "[e]l bajo mundo está asociado a las drogas, el alcoholismo, la prostitución y el juego" (159). Sin embargo, en su expansión territorial, que deja de ser concéntrica para ser lineal,

9 Aunque también existen fronteras y "bifurcaciones siamesas" como un protonormalismo represivo y un normalismo flexible-liberal. En sus límites se desarrollan las sociedades. 
en Bogotá, la ciudad deja de incluir y excluye, sobre todo a un sector migrante del campo que no puede asimilarse a ella. La historia misma presenta aspectos de anomia social y anomia oficial tales como el hecho de que el 9 de abril la policía misma se subleva y se identifica con el pueblo (179):

De manera cíclica, la policía es retratada por Osorio como una institución de control arbitraria con respecto al mundo de la marginalidad urbana. Aparece dominada por el personalismo: su modus operandi, sus criterios de trabajo, sus bajos mandos, los funcionarios medios y bajos, las formas de represión, la corrupción y su bajo nivel cultural, componen la representación que Osorio elabora en torno a la violación institucionalizada de la ley; violación que genera la profundización de los sentimientos de odio colectivos y desdibuja el principio de monopolio de las armas por parte del Estado (186).

Desde este punto de vista, parte de la anomia es consecuencia de la acción del Estado, pero según Neira la solución propuesta por Egon Ernest Bergel ${ }^{10}$, "de domesticar la sociedad anómica mediante el domus, es decir, la construcción del hogar, es una de las demandas más constantes de la novelística de Osorio, quien ve en la ausencia, absoluta o parcial, de la vida familiar un factor de desintegración individual" (160). Por esta razón:

El escritor [Osorio Lizarazo] crea un círculo vicioso en el que la sociedad excluyente sofoca perennemente esas manchas sociales, mientras la masa anómica adquiere perfiles de izquierda y de derecha, ambos reaccionarios a cualquier noción liberal de Estado. [...] Para Osorio, la ciudad se ha dotado de una racionalidad de la exclusión que es, en el fondo, una razón instrumental de la sociedad normalizada. Ésta se ve amenazada por la racionalidad del excluido, que sin arreglo a normas, evadiendo y enfrentando a la ciudad oficial, ha construido un tejido social paralelo (163).

En este contexto de anomia urbana, la narrativa de Osorio Lizarazo ofrece una explicación general de la causa de la violencia así:

Con la vida de la familia García, las múltiples biografías de los criminales de Fuera de la ley y los bajos fondos de El día del odio, Osorio ejemplifica la prolongación histórica del odio y de la discriminación, tanto en el campo como en la ciudad, no como

10 Neira se refiere al texto de Egon Ernest Berge (1955). 
prolongación de una coyuntura política determinada, sino en cuanto la permanencia de la intolerancia como sustancia ideológica de todos los partidos y clases (212).

Además de lo anterior, en medio de esta situación general, según el crítico existen zonas de transición: "[... en Bogotá las zonas de transición se componían de chicherías, canchas de turmequé y prostíbulos. [...] Las zonas de transición y los barrios pobres tenían la misma composición social, aunque, en cada sitio, cada uno de sus miembros actuaba de manera distinta. La sociedad anómica no sólo no respetaba las normas que infructuosamente trataba de imponer la sociedad tradicional, sino que las consideraba ilegítimas" (215). En este espacio maniqueo surge uno simbólico multicultural: "[1]a chicha representa la sociedad anómica y la cerveza la sociedad normalizada y ambas forman parte de un contrapunteo cuya expresión cultural, la sociedad escindida, encuentra en la obra de Osorio Lizarazo su representación más acabada en la literatura colombiana" (225). De esta manera, acorde hasta cierto punto con los postulados estructuralistas de Merton, pero en especial con lo planteado por Girola como situación general de América Latina, al analizar la obra de Osorio Lizarazo, Neira establece como regla la intolerancia generalizada y las fronteras insalvables; por excepción, surgen zonas de transición de la ciudad como efectos anómicos. Por su parte, con Durkheim y Waldmann, el crítico señala la violación institucionalizada de la ley y la desintegración individual como parte esencial del mundo épico. No obstante, el mundo de transición y de frontera al que alude se relaciona con la anomia flexible a la que se refiere Link para el caso de la literatura. En El día del odio los migrantes tanto como la policía se sublevan el 9 de abril en contra de un régimen excluyente y la ciudad en pleno vive un momento de transición hacia otro orden. Además, como Durkheim hablaba del grupo profesional del individuo como un "remedio" para la anomia derivada del trabajo, y la pareja como solución de la anomia conyugal (El suicidio, 1897), según Neira el escritor colombiano Osorio Lizarazo echa de menos la legitimidad del Estado y la vida familiar para saldar la desintegración individual que es la cuna del odio. Y como Duvignaud señalaba la condena del personaje en la novela clásica, se puede advertir con Neira que también el autor de El día del odio "mata" a Tránsito por no ajustarse en ningún modo al orden oficial. Estos elementos pueden advertirse aún en las novelas colombianas que nos interesan. De hecho, para el caso de la novela colombiana de transición entre Osorio Lizarazo y los años noventa, Pöppel advierte:

La solución, finalmente, entendida como [...] la indicación del culpable del crimen, en un sentido más amplio como restitución 
del orden perturbado por el crimen, ha venido cuestionándose por lo menos en los últimos cincuenta o sesenta años. En Colombia no es atrevido afirmar que la solución ha sido puesta en tela de juicio desde los comienzos de la aparición del género y en sus representantes más destacados e innovadores: el colectivo de El misterio del cuarto 215, Manuel Mejía Vallejo o el mismo Gabriel García Márquez $(2001,13)$.

Desde esta perspectiva, la visión clásica de la anomia resulta relativa al momento de explicar la mayor parte de la reciente novela de crímenes en Colombia. Los autores determinados por Pöppel -Manuel Mejía Vallejo, Gabriel García Márquez-son precursores de formas posteriores de entender la anomia en la novela. Para la tesis que aquí se sustenta, justamente la generación de los años 1990-2005 recoge una tradición del género, no sólo de los Estados Unidos sino de América Latina, y ahonda en la relación conflictiva entre individuo y sociedad, entre libertad y control social. De este modo, da cuenta de ese conflicto inicial que denunciaba el romanticismo y de otros derivados de un mundo más complejo de representaciones anómicas.

\section{Los géneros y las novelas de crímenes en Colombia a partir de la anomia}

El escritor español Manuel Vásquez Montalbán señala sobre la novela negra contemporánea:

[E]s una novela basada en un hecho criminal que suscita una investigación, un viaje o merodeo literario que utiliza una retórica y unas claves formales ensayadas por una tradición del género, el cual en un momento determinado es recodificado por novelistas norteamericanos y se convierte en un referente a partir del cual el género se modifica (2009).

Esta definición marca, en primer lugar, la importancia del crimen para hablar de lo negro, y, con base en el modelo norteamericano, la sugerencia de denominar el género como novela de crímenes por encima de otros apelativos como novela policíaca ${ }^{11}$; en segundo lugar, que la

11 Incluso, más allá de la novela latinoamericana negra postmoderna o de otras nominaciones como novela policial revolucionaria o de contraespionaje que, en Cuba, cuenta con el apoyo del régimen. Escritores como Santiago Rafael Rocangliolo, con Abril rojo, Némesis 22, seudónimo del escritor cubano Javier Morán, autor de Choque de Leyendas, y Jaime Collyer, con El infiltrado, texto en que el protagonista narra su propia historia transformándola en la confesión de un culpable, dan cuenta de esto. 
recodificación que se realiza, a partir de referentes clásicos, determina el desarrollo mismo del género, lo cual se puede aplicar al caso de América Latina $^{12}$. En efecto, distintos escritores del continente han puesto énfasis en el hecho mismo del crimen por encima de las instituciones policiales que lo persigan y condenen o del ambiente negro que se exigía convencionalmente para su trama ${ }^{13}$. Este interés verdaderamente recodifica el género y, además, determina el hecho de que tales escritores prefieren indagar en la psicología del criminal (pocas veces en la de la víctima) y, aquí, en un aspecto como el de la culpa, por ejemplo ${ }^{14}$, que interioriza el conflicto anómico o, en términos de Link, ofrece un paisaje distinto de lo que pueda significar la normalidad dominante. En Argentina, escritores como Rolo Diez, Myriam Laurini, José Pablo Feinmann, Osvaldo Soriano y Juan Sasturain ilustran este hecho. La insistencia en el crimen en sus textos lleva a Mempo Giardinelli a definir el género distinguiéndolo del norteamericano:

[...] el género negro norteamericano, y en cierto modo también el europeo, se basan política y filosóficamente en la confianza en el Estado y en la capacidad regenerativa de sus instituciones (el detective funciona como auxiliar de la policía y de la justicia, y entre todos restauran el orden roto por el delito). Lo cual (sic) en América Latina es impensable, porque aquí esas instituciones del Estado son vistas como enemigas ganadas por la corrupción o el negocio de la política, y no suele haber ninguna confianza en ellas. Y hay una tercera diferencia, para mí esencial: y es que para los escritores norteamericanos, y muchos europeos, éste es un género de entretenimiento con el que se puede ganar dinero,

12 Sobre el tema se puede consultar: "El Neopolicial Latinoamericano: de los sospechosos de siempre a los crímenes de Estado", publicado en Encuentro de narrativa policial latinoamericana, Bisama, Adolfo (ed.). Valparaíso: Puntángeles, Universidad de Playa Ancha, 2004 (libro que surge de los aportes realizados por diversos autores en el Encuentro de Narrativa Policial Latinoamericana realizado tanto en Santiago de Chile como en Valparaíso en 2002).

13 Hubert Pöppel (2001) -primero en ocuparse de la novela policiaca en Colombia- habla de la novela del crimen o novela criminal dentro de la novela negra o novela policíaca: este "tipo de narración [... . ] se había separado a lo largo del siglo XIX del género negro [y] sin embargo, volvió a tener conexión con el complejo novela negra/novela policíaca" (13). Para él, esta novela se basa en "la descripción de los preparativos, la consumación y las consecuencias, observadas desde el punto de vista del criminal", y se estructura a partir de una "historia", es decir, de la "sucesión cronológica y lógica de los acontecimientos que llevaron al asesinato" en una relación de efectos y causas (23). Además, esta novela es "abierta" porque contiene elementos ajenos al plot, por ejemplo (24); tiene como protagonista a un antihéroe, criminal; es de Action (con partes narrativas de las novelas que cuentan crímenes en la terminología de Schulz-Buschhaus $(1975,1-5)$ ) y tematiza un "desorden" fundamental (26).

14 Tony Hilfer analiza la estructura y los tipos de la crime novel a partir de la culpa en el caso de la novela anglosajona (1990). 
mientras que para nosotros es un género literario capaz de denunciar vigorosamente la injusticia (2004).

En México algunas novelas de Vicente Leñero, como Asesinato: el doble crimen de los Flores Muñoz, y en Brasil, Rubem Fonseca, con novelas como Agosto, así lo confirman. Asimismo lo hacen autores como Luis Sepúlveda, Roberto Bolaño y Ramón Díaz Eterovic en Chile; Mario Delgado en Uruguay, Renée Ferrer en Paraguay, con La Querida, y Leonardo Padura Fuentes y Lorenzo Lunar en Cuba, quienes recrean la dialéctica que existe entre crimen y poder en el Continente. Lo mismo sucede en El Salvador con Rafael Menjívar Ochoa, autor de Los años marchitos, Los héroes tienen sueño y De vez en cuando la muerte, textos que proponen originales lecturas de conductas que de una u otra manera se han valorado, o bien se valorarán luego, como delitos, y en el proceso de establecimiento y caducidad de la punibilidad permiten fijar una idea de lo que define la sociedad en un momento dado como crimen. En tal sentido, para buena parte de la novela del continente, Margarita Rojas González (2008) afirma: "En la narrativa contemporánea el género policiaco remite directamente al crimen y a la violencia, que se desarrollan con las coordenadas propias del escenario urbano nocturno. Ejemplos son las series de novelas del detective Héctor Belascoarán Shayne, de Paco Ignacio Taibo II, el detective Heredia, de Ramón Díaz Eterovic, y la de Mario Conde, el detective bibliófilo de Leonardo Padura" (597). Asimismo, el propio Paco Ignacio Taibo II (2003) hace alusión al carácter de reflejo de las complejidades marginales de las sociedades latinoamericanas que posee esta clase de novela en América Latina y, además, habla de los grandes traumas sociales: "Mi aporte a la política es mi formación literaria, y de la combinación de Robin Wood y Bertold Brecht puedo inferir que es mejor robar un banco que fundarlo". Con esta dinámica, también en Colombia surge un conjunto de obras que se pueden denominar novelas de crímenes, pues se subsumen en tres tipologías de la anomia social de la que dan noticia.

\section{La ausencia de ley en la novela}

Existen novelas de crímenes en Colombia en que se da cuenta de una situación generalizada de desorden en la organización social al punto que el mundo novelesco parece el mundo del caos o el mundo de la anarquía. Allí ni autor ni protagonista ni personajes creen en un orden legítimo y la situación generalizada de anomia se impone sobre los individuos como situación de ilegitimidad. La novela describe 
un mundo de anomia flexible donde es el lector el que puede actuar como detective.

El capítulo de Ferneli, de Hugo Chaparro Valderrama (Bogotá, $1961)^{15}$, por ejemplo, recrea una atmósfera generalizada de crímenes, terror y muerte en la Bogotá - "Una ciudad real de la que era preferible tener una imagen fantástica para poder soportarla" (63)- de 1979 (fecha del primer hecho espantoso) a 1990. En efecto, la novela termina con el lugar y la fecha que contextualiza la anécdota: "Bogotá, junio 1989/ julio 1990" (285). En este espacio literario, Ferneli ${ }^{16}$, el protagonista del relato, es a la vez su escritor, escribano o cronista (243); y el intelectual ${ }^{17}$, el detective $(20,118)^{18}$, el testigo y cómplice (105) o la víctima de la delincuencia organizada -"sumido en una situación de

15 Es escritor, historiador y crítico cinematográfico y literario. Trabajó en el periódico El Espectador en la época del asesinato de su director Guillermo Cano (1986). Ha publicado además las novelas Si los sueños me llevaran hacia ella (1999) y No me olvides cuando mueras (2007), los libros de ensayos Lo viejo es nuevo y lo nuevo es viejo y todo el jazz de New Orleans es bueno (1992), Alfred Hitchcock. El miedo hecho cine (2005) y Del realismo mágico al realismo trágico (2005); dos libros de poemas que han merecido el Premio Nacional de Poesía otorgado por el Ministerio de Cultura de Colombia: Imágenes de un viaje (1993) y Para un fantasma lejano (1998); un cuento infantil, "El amor de una jirafa" (2004), y una antología de testimonios cinematográficos, El evangelio según Hollywood (2005). Fue becario del International Writing Program de la Universidad de Iowa (Estados Unidos) durante el otoño de 2002. En la actualidad, es columnista de temas cinematográficos en el periódico El Espectador y es director de los Laboratorios Frankenstein.

16 Ferneli puede ser concebido como un alter ego de Chaparro Valderrama. "Ferneli no era un detective. Sólo un lector que amaba los detectives, las historias de detectives y los juegos con la muerte a la que se veían enfrentados por obra y gracia de sus autores" (165). "No es un mundo muy fragante, pero es el mundo en el que vivimos y ciertos escritores de mente reacia y frío espíritu de desapego pueden dibujar en él tramas inteligentes y hasta divertidas. No es extraño que un hombre sea asesinado, pero a veces resulta extraño que lo asesinen por tan poca cosa y que su muerte sea el sello de lo que llamamos civilización. Y todo esto sigue sin ser suficiente'. / Una cita que ocupaba un lugar de honor en la cartelera de Ferneli y que definía con exactitud la corrupción del sistema legal y el estado de las cosas por el que atravesaba la ciudad. Una muestra de agudeza literaria que podía ser nada cuando alguien padecía en carne propia incluso la más suave de las violencias. Sin embargo, Ferneli creía ciegamente en la ficción y en la forma como la ficción podía ennoblecer toda realidad por más trágica que fuera o hacer de la tragedia un motivo para crear todo tipo de juegos literarios. La imaginación se convertía entonces en el último refugio a situaciones como aquella en la que se encontraba" (69). Al final de la novela, hay una foto del personaje Ferneli, que en realidad es del autor, Hugo Chaparro Valderrama (268).

17 "Su biblioteca exquisita, la forma como observaba el mundo a través de la lupa de su erudición, la publicación regular de historias o artículos con los cuales trataba de aclararse a sí mismo o a un posible lector el lúgubre panorama que en el momento era norma, lo habían llevado a vivir en una ficción que se había convertido en su realidad cotidiana" (25).

18 Sobre esto, Pöppel afirma: "Las novelas de Chaparro y [Luis Femando] Veissimo tienen como figuras centrales detectives no convencionales que escriben de manera paralela sobre su investigación y otros textos policíacos. [...] Por un lado, se trata de novelas que se sitúan después del boom, con todas las implicaciones de tipo narrativo e intertextual; y, por otro, son novelas profundamente políticas, en cuanto investigan sobre épocas claves en la historia reciente de sus respectivos países: el golpe militar de 1964 en Brasil y la nueva violencia en Colombia a partir de finales de los años setenta" (198-199). 
la que aún no comprendía nada" (28)-; es incluso el chivo expiatorio (243) que plasma en el símbolo de un monstruo la situación de terror generalizado que vive la ciudad y el país en general. Este personaje es, además, un lector $(20,165)$ que "amaba los detectives, las historia de detectives y los juegos con la muerte a la que se veían enfrentados por obra y gracia de sus autores. Personajes que trataban de comprender, a través de individuos clásicamente rudos y en conflicto permanente con una ley burocrática y corrupta, el malestar de una época" (165). Desde este complejo punto de vista anómico, como señala Pöppel, es el lector mismo el que debe cumplir la función de detective "para relacionar los indicios de los paratextos ${ }^{19}$ entre sí y con el relato" (243). ${ }^{20} \mathrm{La}$ adaptación del afiche publicitario de la película Frankenstein: The Man Who Made a Monster (1931) -basada en la novela escrita en 1818 por Mary Shelley, dirigida por James Whale y adaptada para el cine por Peggy Webling- desde un primer momento demuestra ese propósito del escritor (plasmar en la ficción toda clase de miedos): "Un diseño basado en este Frankenstein original, Frankenstein que, como Ferneli, también construyó su monstruo" (249), advierte el escritor. Este cartel transformado del clásico cinematográfico presenta la novela como una película de terror con su propio monstruo y personajes literarios que son los clásicos del género que le sirven de base: "El capítulo de Ferneii. Novela policíaca e ilustrada de los últimos tiempos. Con Dashiell Hammet, Raymond Chandler, Graham Greene, Julio Cortázar, John Fante, Rubem Fonseca, Daniel Defoe y Anne Rice" (11). ${ }^{21}$ Y luego, para

19 Además, la carátula escogida para la novela de Chaparro Valderrama (el cuadro de El imperio de las luces (1954), del pintor surrealista Rene Magrite (1898-1967)), así como los apéndices "Ferneli vuelto a visitar" y "Adivine el personaje - Solución" permiten cumplir con el propósito del escritor. La primera es una representación del claroscuro del día y la noche y del contraste entre la vigilia y el sueño, que ilustra el ambiente difuso de la novela y da una idea de la sinuosa psicología de su personaje Ferneli. Los segundos, que incluyen numerosos textos y fotos o ilustraciones que complejizan aún más el elemento del terror en el texto -como la columna sobre las matanzas en Colombia en 1988 de Antonio Caballero, transcrita en la última parte del texto (279)-, son elementos que lo desarrollan. Gracias a estos y otros, el monstruo surge entonces como causa y consecuencia, como elemento externo e interno de la novela y, en síntesis, como símbolo del ambiente social y de la piscología del personaje principal.

20 Los epígrafes de los escritores norteamericanos Charles Beaumont (1929-1967) ("Lo que hacemos nosotros, los escritores de literatura fantástica, es crear substitutos de miedo en los cuales creer") y Edgar Lawrence Doctorow (1931) ("Los criminales consagrados viven en el extremo de la civilización, donde los modales y la ética se simplifican y el impulso subyacente de nuestros orígenes tribales, primitivos, se abren paso") (9), del mismo modo que la Nota del autor ("Todos los personajes son tomados de la vida real. Cualquier coincidencia con la ficción aquí narrada es puramente accidental. Y siguiendo el proverbio de Caín, aquí empiezo, Showtime"), así lo demuestran.

21 Además, se señala que la novela es "producida" por una empresa cinematográfica denominada "Laboratorios Frankestein" (Grupo que en el contexto real del autor se dedica a la crítica de cine con sede en Bogotá), que es "protegida" por Ernesto Elvia y Genoveva-La-Mar, a quienes 
explicar mejor la naturaleza de este monstruo de Ferneli, el narrador advierte:

El suyo era así un espectro entre los espectros y no era una aparición exclusiva de sus pesadillas: sus visiones hacían parte de un horror colectivo, tolerado con la dificultad o la resignación de alguien condenado a un vicio; un horror que asaltaba a una comunidad estafada en su buena fe por una violencia sin límites. Y la escritura-exorcismo, conjuro o terapia- permitía aniquilar a los peores demonios o, por lo menos, colocarlos en su sitio, aunque fuera en el mundo imaginario y real de los libros (210).

De este modo, el monstruo plasmará las pesadillas del personaje y, al mismo tiempo, el horror colectivo. Frente a él, la novela surge como un método para aniquilarlo o, por lo menos, para colocarlo en su sitio. Este proceso o "exorcismo, conjuro o terapia" es el que define la ruta de su argumento, pues es a través de la escritura como se llega a vencer al monstruo.

Esta resolución novelesca de El capítulo de Ferneli se opone no obstante a los casos particulares de la segunda clase de anomia que acusan otros textos colombianos de los últimos años.

\section{Situaciones épicas que derivan de la carencia de normas sociales}

Diferente del supuesto anterior, la carencia normativa como ambiente de la novela se presenta en los casos en que una situación anómala, que no está regulada por la ley, afecta a un individuo y el hecho parece no importarle a nadie, ni siquiera al narrador. A diferencia de la anomia derivada de la ausencia de ley, en este caso es la situación particular la que no está amparada por una ley y, en tal virtud, el individuo (para el caso el personaje) carece de apoyo social, familiar o aun psicológico para reconstruir su confianza en el sistema (como lo exigía Durkheim). En ese momento un hecho social carece de definición jurídica y es el sujeto el que sufre esta carencia.

se dedica el libro (7). Este elemento inicial (reiterado en la novela por las numerosas tarjetas que se deslizan por el resquicio de la puerta del apartamento del personaje y, al final, cuando se transcribe el contenido de la última tarjeta de los Laboratorios (284)) corrobora el carácter de novela de crímenes con elementos cinematográficos. 
Dentro de las novelas de este tipo se puede incluir Rosario Tijeras (1999), de Jorge Franco Ramos ${ }^{22}$. En ella, desde un principio se da cuenta de la situación anómica que vive Antonio, que es a su vez el narrador, un muchacho de cierto nivel social que tiene acceso al mundo del hampa, es decir, a la zona de frontera: luego de ejecutar uno de sus trabajos, la protagonista Rosario, que es sicaria, es llevada por él a un hospital con heridas de bala. Mientras Antonio espera en la sala del hospital, se relatan algunos sucesos del tiempo que vivió cerca de ella. Antonio da cuenta de la relación sentimental de Emilio, su amigo, y Rosario, y el hecho de que luego de un breve romance y de un amor no correspondido, surgió una curiosa amistad entre él y Rosario. La narración se da en torno a la espera de la noticia de la muerte o salvación de la protagonista, quien estaba en conexión con los altos capos del narcotráfico del momento, 'Los Duros', y en uno de sus trabajos resultó herida:

Estuvo metida [...] con los duros de los duros [...] Ellos la bajaron de su comuna, le mostraron las bellezas que hace la plata, cómo viven los ricos, cómo se consigue lo que uno quiere [...] La trajeron hasta donde nosotros nos la trajeron nos la mostraron [...] ella ni corta ni perezosa se dejó mostrar, sabía quiénes éramos, la gente de bien los buenos del paseo, y le gustó el cuento y se lo echó a Emilio, que se lo comió todo (24).

Una vez narra los hechos vividos por él con Rosario y sus allegados, Antonio recibe la noticia de la muerte de Rosario en la sala de espera. De tal modo, el muchacho del mundo legal se ve inmerso en la situación anómica. Aunque respecto de los delitos de la protagonista no pase nada, Antonio da cuenta de su experiencia en la línea de transición de un mundo normado a otro anómico. El conflicto se presenta cuando observa como un testigo inconsciente el mundo de ilegalidad: "[...] No recuerdo exactamente el orden como ocurrieron ni el tiempo en que se desarrollaron [...] creo, fue el estrépito de la puerta abriéndose de un solo golpe, después el apartamento invadido de soldados armados [...]" (187). En este punto de la narración, el mundo ilegal irrumpe en el mundo oficial, pero tal hecho no alcanza a ser asimilado como

22 Jorge Franco nació en Medellín en 1962, realizó estudios de dirección y redacción de cine en el London International Film School en Londres, y de Literatura en la Universidad Pontificia Javeriana de Bogotá; además, participó en varios talleres literarios. Empezó su carrera como escritor en 1991 y recibió el premio Nacional de Narrativa Pedro Gómez Valderrama por su colección de cuentos titulada Maldito Amor (1996). Con Mala Noche (1997) obtuvo el primer premio en el Concurso Nacional de novela "Ciudad de Pereira". Con Rosario Tijeras (1999), ganó la Beca Nacional de Novela del Ministerio de Cultura en 1997 y el premio Dashiell Hammett (2000). En 2001 publicó Paraíso Travel. 
problemático por el personaje, pues, como en la novela romántica, es la muerte la que resuelve las cosas y deja en otra dimensión la promesa de una sanción para la criminal: "Tengo que dejarla, mirarla por última vez y dejarla, la última vez que estoy con ella [...]" (196), dice luego el narrador, que vive inconscientemente la frontera entre el mundo legal y el mundo anómico.

En este caso, la novela sugiere la reflexión en torno a la carencia de normas sancionatorias, tanto para los delincuentes de cuello blanco como para la delincuencia marginal. Asimismo, queda sin condena la complicidad de Antonio y el crimen es una entidad inmersa en un proceso de anomia social y anomia del individuo, que a su vez marcha al margen de la sociedad que se recrea en la novela. Esta resolución podría incluirse dentro del modelo clásico al que se refiere Duvignaud: es en el otro mundo donde podría pensarse la punición. Rosario muere por circunstancias anómicas y este final resuelve la novela, tal como en las obras clásicas de Don Quijote y Madame Bovary. La anomia individual, es decir, las causas de la situación son individuales y plantean una trascendencia.

Sin duda, este caso de Rosario Tijeras se diferencia de la anomia por degradación de las normas existentes que hacen que el individuo viva situaciones límite, tal como se analiza a continuación.

\section{Situaciones épicas que derivan de la degradación de normas sociales}

Las normas de una estructura jurídica preexistente pueden caer en desuso o en un proceso de degradación. Eso se puede ver en situaciones como la banalización del crimen. En este caso, la norma existe pero es su inobservancia -como analiza Waldmann- la que lleva a que esa existencia sea nominal.

Como ilustración de esta clase de anomia, se puede analizar la novela Memorias de un hombre feliz (2000) de Darío Jaramillo Agudelo23.

23 Nació en Santa Rosa de Osos, Antioquia, el 28 de julio de 1947. Es escritor y poeta. Estudió derecho en la Universidad Javeriana de Bogotá. Ha publicado los libros de poesía: Historias (1974), Tratado de retórica (1978), Poemas de amor (1986), Del ojo a la lengua (1995), Cantar por cantar (2001), Gatos (2003) y "Cuadernos de música" (2008); y de prosa: La muerte de Alec (1983), Guía para viajeros (1991), Cartas cruzadas (1995), Novela con fantasma (1996), Memorias de un hombre feliz (1999), El juego del alfiler (2002), Historia de una pasión (2006) y La voz interior (2006). Recibió el Premio Nacional de Poesía en 1978 y fue candidato al Premio Rómulo Gallegos del año 2003. 
Aunque en el mundo épico de este texto existe la ley, pues el homicidio es legalmente castigado, el hecho cae en un estado de banalización tal que Tomás, un hombre común y corriente, lo comete con la frialdad de un mecanismo de reloj. Este personaje cuenta su vida en los últimos 30 años, desde cuando obtiene un trabajo hasta su matrimonio con Regina García, dueña de "La Empresa" y 10 años mayor que él. El narrador reconstruye uno a uno los pasajes que marcaron los momentos más importantes de su vida familiar y laboral durante los 25 años que estuvo casado con Regina y expone los motivos que lo llevaron a asesinarla. Así, desde el primer capítulo informa que él mató a su esposa y va hacia el pasado para reconstruir la historia. "Créame. Soy un hombre feliz y en las páginas que siguen me propongo contarle cómo alcancé la felicidad. En otras palabras, esta es la historia de cómo asesiné a mi esposa" (12). Así, el narrador da cuenta del efecto y de su estrategia minuciosa, como si se tratara de poner en funcionamiento un delicado mecanismo de relojería. Él tiene conocimiento de que Regina es alérgica a las aspirinas y aprovecha entonces esta afección para ejecutar el plan hasta lograr su objetivo. Con claridad y con una tranquilidad pasmosa, Tomás justifica su homicidio como una legítima defensa frente a un verdugo que ha manipulado su propia vida: "El horror metafísico al descubrir un ser ajeno entre mi pellejo, me impulsó a prescindir de su autora. Era la única manera de expulsarlo y de permitirle al verdadero y latente Tomás que sobreviviera. Ahí se ve con claridad: era su vida o la mía. La eliminé en defensa propia" (75). El personaje recorre así un curioso camino que lo lleva de víctima a criminal y, de acuerdo con su perspectiva, a héroe sin culpa ni remordimiento alguno ${ }^{24}$.

La injusticia que debe ser reparada es la invasión de Regina a mi intimidad y la consecuente invención de un Tomás de trapo que desplazó al verdadero Tomás. Regina es la culpable. Ella es la primera causa y por eso, como corolario, la dinámica de los hechos lleva a que Regina deba ser suprimida. Claramente, yo soy la víctima que cobra justicia (250).

Así, Tomás siempre se mueve dentro de lo legal, pero el cambio que quiere lo lleva a buscar soluciones al margen de lo legal y lo "correcto":

24 Sobre este tema me parece interesante la clasificación de Salvador Vásquez de Parga de la novela que denomina criminal (1986): [...] el detective se convierte en criminal, o el criminal en detective. Más difícilmente, el criminal llega a ser la víctima, pero puede ocurrir así que la víctima llegue a ser criminal [...] el detective ha de ser víctima o la víctima pasa a ser detective" (31). Para el caso de esta novela, desde su punto de vista el criminal se considera la víctima y dada la condición de Memorias del libro el lector pasa a ser su cómplice. 
Me preocupa, a veces me preocupa, no siempre, más bien poco -lo admito-, pues suelo preocuparme muy rara vez, me inquieta que piensen que estoy recomendando el asesinato como fórmula para la felicidad. No es así de simple. Ante todo, no propongo el asesinato y, luego, no creo que el asesinato sea la fórmula de la felicidad.

Está visto que los asesinatos son el principio de una desgracia mayor de la que remedian. Sin contar que el asesinato mismo suele ser muy vulgar, muy ruidoso, muy contaminante de manchas tan persistentes como la sangre. "No lo recomiendo para circunstancias como la mía -asesinar al cónyuge- porque en todos los casos el homicida está tan cargado de rabia que comete el crimen con demasiada torpeza, sin la sangre fría que se necesita para abordarlo como un proyecto de ingeniería [...]. Ahora, mientras escribo, reaparece el pensamiento de que no soy un homicida. Yo no me proponía sacarla de la vida: me proponía sacarla de mi vida, que es distinto (314).

Sin duda, al leer el libro que es el resumen de unas "memorias", el lector se hace cómplice del protagonista (curiosa situación anómica que está fuera de la novela) pues llega a comprender e identificarse con los móviles del asesino. Él es el confidente de un crimen impune: "Usted, lector, es mi cómplice. Tampoco usted soportaría la invasión de su intimidad, la supresión de su territorio, la omnipresencia cargante de esa tortícolis humana que fue Regina García" (248). Hasta este punto se produce la inversión de la norma social. La ausencia de sanción se generaliza para dar cuenta del modelo social de que se da noticia. Así lo explica el personaje al lector:

Ni a usted ni a mí nos importa que en un orden muy remoto de la ética sea malo vengarse, tomar justicia por mano propia, ajusticiar, como hice yo en sentido literal. A usted no le importa porque así son todas las películas: el héroe -apabullado, atropellado, aplastado con desconsideración, con injusticia-, el héroe cosificado saca fuerzas de su debilidad y bendecido por una santa ira que lo impulsa a devolver la situación a un orden más equitativo, cobra justicia. Final feliz de la víctima que elimina al malo de la película (249).

En este caso, la novela sugiere la reflexión en torno al crimen como resultado de una situación anómica de degradación de las normas que existen. Las sanciones están previstas para los delitos pero el sistema judicial es inoperante y el delincuente se mantiene incólume: en po- 
cos casos se considera a sí mismo culpable o responsable ante una ley nacional.

A partir de lo anterior, que es sólo una muestra representativa de las novelas de crímenes de los últimos años en Colombia, se puede proponer entonces una caracterización del género de la siguiente manera:

\section{Caracterización del género}

1. La novela de crímenes en Colombia se diferencia del género negro, la novela policíaca tradicional, el "neopolicial" latinoamericano o la novela postmoderna pues se explica a partir de la anomia. En ella se ofrece la descripción épica de una dinámica social de ausencia de ley o de situaciones que derivan de la carencia de normas o de su degradación. Mientras el primer caso alude a una situación generalizada, común para un Estado anómico (Girola, Waldmann), el segundo alude a la carencia de una norma para un caso dado debida en buena parte a la condición particular del individuo (conforme a las pautas de Durkheim y Merton), y el tercero a la degradación de una norma en particular, que en buena parte se inscribe dentro de la lógica de los oprimidos y la normalidad (Girola, Neira, Link).

2. Mientras que en la novela clásica se habla de deseo infinito del escritor que lo lleva a anticipar otra realidad (Durkheim, Duvignaud), en general la novela de crímenes en Colombia parte de una realidad de por sí incomprensible y a la que resulta difícil oponerse, ni siquiera como parte de un deseo infinito. De ahí que los casos de restablecimiento de un orden a la manera clásica sean excepcionales y se ubican en la anomia por carencia de una norma para un caso dado. Aquí hasta cierto punto un orden se restablece.

3. Mientras en la novela clásica se condena al personaje (Duvignaud), en general en la novela de crímenes difícilmente se logra determinar un culpable, aprehenderlo o, mucho menos, restablecer por este medio un orden. Ante todo, los casos de anomia por ausencia de ley y degradación de una norma así lo demuestran. En este sentido, el género hace alusión a los problemas más acuciantes de las sociedades latinoamericanas, una anomia flexible (Link).

4. Como señalan Girola y Waldmann para la realidad histórica de América Latina, en su literatura los paradigmas clásicos también se actualizan: en la novela colombiana el estado de anomia no es excepcional y el deseo del personaje, de la sociedad épica, del narrador y el autor, 
La anomia en las novelas de crímenes en Colombia / Gustavo Forero Quintero

es comprender las causas de esa realidad anómica; más aún, entender una dinámica social que carece del punto de referencia confiable de un orden preestablecido. Como señala Vásquez Montalbán, el hecho supone una recodificación del género clásico.

5. A falta de orden en la realidad que le sirve de marco, el escritor no tiene ese deseo humano de subvertir y sus personajes se encuentran ellos mismos dentro de un ambiente de anomia que determina sus conductas y hace relativa su capacidad de rebeldía o subversión.

Por lo anterior se puede advertir que la metodología sociológica de la anomia tiene sus beneficios al aplicarse en la literatura. A partir de esta herramienta conceptual se hace posible la descripción de la novela de crímenes en Colombia. El viejo común denominador de la violencia en Colombia, como fruto conflictivo del proceso de urbanización y modernización, tiene su más significativa vertiente en la novela de crímenes contemporánea y anuncia una nueva novela que plantea situaciones límite de una sociedad escindida.

\section{Bibliografía}

Berge, E. (1955). Sociología urbana. Buenos Aires: Bibliográfica Argentina.

Bisama, A. (ed.). (2004). Encuentro de narrativa policial latinoamericana, Valparaíso: Puntángeles, Universidad de Playa Ancha.

Brooks, P. (2000). Troubling Confessions: Speaking Guilt in Law and Literature. Chicago: University of Chicago Press.

Cancino, A. J. (1973). El Derecho penal en la obra de Gabriel García Márquez. Bogotá: Universidad Externado de Colombia.

Chaparro Valderrama, H. (1992). El capitulo de Ferneli. Bogotá: Arango Editores.

Diccionario de la Real Academia de la Lengua Española (2006). Disponible en http://buscon.rae.es/draeI/. Consultado el 17 de junio de 2006.

Diccionario Cuyas (1974). Barcelona: HYMSA.

Diccionario Collins (2001). Barcelona: Grijalbo.

Duvignaud, J. (Traducción de Daniel Laks). (1990). Herejía y subversión. Ensayos sobre la anomia. Barcelona: Icaria. 
Durkheim, E. (1967). Le suicide. Étude de sociologie. París: Les Presses universitaires de France.

(Trad. David Naldavsky). (1967). De la división del trabajo social. Buenos Aires: Schapire S.R.L.

(1998). El suicidio. Madrid: Akal.

Forero, G. (2005). "La metonimia de Colombia en La Rambla paralela de Fernando Vallejo". En Grafía, Bogotá: Universidad Autónoma de Colombia, pp. 47-59.

(2006). "Indefiniciones y sospechas del género negro". II Simposio Internacional de Novela Negra. En Hojas Universitarias. Bogotá: Universidad Central, pp. 124-138.

(2007). "Del delito común al delito político en Los ojos del basilisco de Germán Espinosa". En Estudios de Literatura Colombiana. Medellín: Universidad de Antioquia, pp. 37-57.

(2008). "La culpa en la novela histórica de Germán Espinosa". En Germán Espinosa: Señas del amanuense. Bogotá: Pontificia Universidad Javeriana, pp. 77-94.

(2009). "La anomia en la novela de crímenes en Colombia (19902005): El caso de Comandante Paraíso de Gustavo Álvarez Gardeazábal". En Lingüística y Literatura. Medellín: Universidad de Antioquia, pp. 72-85.

(2010). "La novela de crímenes en América Latina: Hacia una nueva caracterización del género". En Lingüística y Literatura. Medellín: Universidad de Antioquia, pp. 49-61.

Franco Ramos, J. (1999). Rosario Tijeras. Bogotá: Plaza y Janés.

Giardinelli, M. (31 de octubre de 2004). "Sobre el género negro". http:// www.mempogiardinelli.com/home.htm. Consultado el 5 de noviembre de 2009.

Girola, L. (2005). Anomia e individualismo. Del diagnóstico de la modernidad de Durkheim al pensamiento contemporáneo. Barcelona: Anthropos, Universidad Autónoma Metropolitana.

Häberle, P. (1983). Das Grundgesetz der Literaten. Der Verfassungstaat im (Zerr-) Spiegel der Schönen Literatur. Baden-Baden: Nomos.

(2004). "Poesía y derecho constitucional: Una conversación". En Punto de vista 17, Fundació Carles Pi i Sunyer D’Estudis Autonòmics y locals. Barcelona: febrero. 
La anomia en las novelas de crímenes en Colombia / Gustavo Forero Quintero

Hilfer, T. (1990). The Crime Novel. A Deviant Genre. Austin, University of Texas Press.

Jaramillo Agudelo, D. (2000). Memorias de un hombre feliz. Bogotá: Alfaguara.

Leenhardt, J. (1973). Lecture politique du roman. La Jalousie d'Alain RobbeGrillet, Paris: Éd. de Minuit.

Link, J. (2006). Versuch über den Normalismus. Wie Normalität produziert wird/ Göttingen: Vandenhoeck \& Ruprecht.

Lukács, G. (1955). (Trad. de Jasmin Reuter). La novela histórica. México: Era, 1977.

Merton, R. (1964). (Trad. de F. Torner y R. Borques). Teoría y Estructuras Sociales. México: FCE.

(1968). "Continuities in the Theory of Social Structure and Anomie". En Social Theory and Social Structure, N.Y: Free Press.

(2002). (Trad. de Cristóbal Torre Albero): "La división del trabajo social de Durkheim", en REIS. Revista Española de Investigación Sociológica. No. 99, jul-sept.

Martínez Sahuquillo. I. (1998). "Anomia, extrañamiento y desarraigo en la literatura del siglo XX. Un análisis sociológico". En REIS. Revista Española de Investigación Sociológica, No. 84/98, pp. 223-242.

Mendoza, M. (2007). Satanás. Bogotá: Seix Barral.

Neira, E. (2004). La gran ciudad latinoamericana. Bogotá en la obra de José Antonio Lizarazo. Medellín: EAFIT.

Pöppel, H. (2001). La novela policíaca en Colombia. Medellín: Universidad de Antioquia.

Rojas González, M. (2008). "La ciudad y la noche. La nueva narrativa latinoamericana". En Acosta, Carmen Elisa et al. Literatura, prácticas críticas y transformación cultural. JALLA (2006). Bogotá: Universidad Javeriana, pp. 593-604.

Schulz-Buschhaus, U. (1975). Formen und Ideologien des Kriminalromans. Frankfurt/M.: Athenaion.

Taibo II, Paco Ignacio. (2003). Entrevista. En Semana negra de Gijón, 27 de abril de 2003. http://axxon.com.ar/not/125/c- 
125InfoTaiboII.htm. Consultado el 20 de abril de 2011.

Vallejo, Fernando (2006). La virgen de los sicarios. Madrid: Punto de Lectura.

Vásquez de Parga, Salvador (1986). De la novela policíaca a la novela negra. Los mitos de la novela criminal. Barcelona: Plaza y Janés.

Vásquez Montalbán, Manuel. Entrevista de la revista Lata de zinc, octubre de 2007. Oviedo, Colectivo cultural Lata de Zinc. Disponible en: http://latadezinc.googlepages.com/ LDZ07.pdf. (Consultada el 5 de junio de 2009).

Waldmann, P. (2003). (Trad. de Monique Delacre). El Estado Anómico. Derecho, seguridad pública y vida cotidiana en América Latina. Caracas: Nueva Sociedad.

(2007). (Traducción de Monique Delacre). Guerra civil, terrorismo y anomia social. El caso colombiano en un contexto globalizado. Bogotá: Norma. 